\title{
Spinal Radiographic Changes in Ankylosing Spondylitis: Association with Clinical Characteristics and Functional Outcome
}

\author{
ANNELIES BOONEN, BERT vander CRUYSSEN, KURT de VLAM, SERGE STEINFELD, CLIO RIBBENS, \\ JAN LENAERTS, FILIP Van den BOSCH, HERMAN MIELANTS, LODE DEWULF, and NATHAN VASTESAEGER
}

\begin{abstract}
Objective. To determine which patients with ankylosing spondylitis (AS) have radiographic spinal damage and to investigate the relation between radiographic spinal changes and limitations in physical function.

Methods. A cross-sectional nationwide study in Belgium of patients with AS under the care of a rheumatologist. The treating physician completed a questionnaire including clinical disease manifestations and laboratory findings (HLA-B27 and C-reactive protein), and classified spinal radiographs into 3 categories: (1) no AS-related spinal abnormalities; (2) syndesmophytes; and (3) spinal ankylosis. Patients completed the Bath AS Disease Activity Index (BASDAI) and the Bath AS Functional Index (BASFI). Ordinal regressions were performed to quantify the relationship between clinical manifestations and spinal radiographic changes. Generalized linear models were computed to quantify relationships among clinical manifestations, radiographic spinal changes, and functioning (BASFI).

Results. A total of 619 patients fulfilled modified New York criteria for definite AS and had evaluable radiographic data; 68\% were male and disease duration was 17.5 (SD 12.2) years. Male sex, younger age at symptom onset, and hip involvement were associated with radiographic changes; but HLA-B27, peripheral arthritis, and extraarticular disease status (uveitis, psoriasis, and inflammatory bowel disease) were not. Older age, BASDAI, hip involvement, and spinal change contributed to BASFI; but sex, disease duration, peripheral arthritis, and extraarticular manifestations did not.

Conclusion. Radiographic spinal changes in patients with AS are seen more often in men and those with hip involvement. BASFI status indicates the influence of radiographic changes and hip involvement, but does not reflect the presence of peripheral arthritis and does not differ between men and women. (First Release May 15 2009; J Rheumatol 2009;36:1249-55; doi:10.3899/jrheum.080831)
\end{abstract}

Key Indexing Terms:

ANKYLOSING SPONDYLITIS $\quad$ GENDER RADIOGRAPHY HEALTH STATUS

Ankylosing spondylitis (AS) is considered prototypical for the group of chronic rheumatological conditions referred to as the spondyloarthropathies. The hallmark of the disease is inflammation of the sacroiliac joints resulting in progressive

From University Hospital, Maastricht, The Netherlands; Gent University Hospital, Gent; University Hospital, Leuven; Erasme University Hospital, Brussels; Hôpital Sart Tilman, Liège; Virga Jesse Hospital, Hasselt; and Schering Plough, Brussels, Belgium.

Supported by Schering-Plough Belgium. Dr. Vander Cruyssen is a postdoctoral researcher supported by a research grant of FWO Flanders.

A. Boonen, MD, PhD, University Hospital Maastricht; B. Vander

Cruyssen, MD, PhD, Gent University Hospital; K. de Vlam, MD, PhD,

University Hospital, Leuven; S. Steinfeld, $M D, P h D$, Erasme University

Hospital; C. Ribbens, MD, Hôpital Sart Tilman; J. Lenaerts, MD, Virga

Jesse Hospital; F. Van den Bosch, MD, PhD; H. Mielants, MD, PhD,

Professor, Gent University Hospital; L. Dewulf, MD; N. Vastesaeger, MD, Schering Plough, Brussels, Belgium.

Address reprint requests to Dr. A. Boonen, Department of Internal Medicine, Division of Rheumatology, Maastricht University Medical Centre, PO Box 5800, 6202 AZ Maastricht, The Netherlands.

E-mail:a.boonen@mumc.nl

Accepted for publication January 29, 2009. structural changes that are eventually evaluable by conventional radiography ${ }^{1,2}$. Apart from sacroiliitis, AS is clinically heterogeneous, which adds to the challenge in understanding the pathophysiology and assessing all aspects of its clinical outcome. Sacroiliitis, spondylitis, peripheral arthritis, enthesitis, and involvement of shoulders or hips (known as root joints) contribute to the articular burden of AS. A number of extraarticular manifestations, including uveitis, psoriasis, and inflammatory bowel disease (IBD) can complicate the clinical presentation of the disease ${ }^{3}$.

Spinal syndesmophyte formation and ankylosis are the most striking features of AS and can be seen on conventional radiography. Only a few studies have investigated the relation between the clinical characteristics and radiographic spinal changes ${ }^{4-6}$. The association of uveitis with spinal change has been investigated in 3 studies, but the results are conflicting ${ }^{7-9}$. Brophy, et al found no association of IBD or psoriasis with spinal changes ${ }^{5}$. To our knowledge, the relation between the articular manifestations and ankylosis has never been addressed. In addition to the disease-related clin- 
ical manifestations, intrinsic patient characteristics (e.g., sex) can be associated with the presence of radiographic changes. In this regard, all but one of 13 studies showed that women had fewer radiographic changes in lumbar and thoracic spine, independent of the scoring method applied ${ }^{6}$.

There are few studies addressing the influence of radiographic spinal changes on patient outcomes. Taylor, et al ${ }^{10}$ found that ankylosis correlated with more pain, stiffness and sleep disturbance; and Lee, et al and Doran, et al reported that radiographic status was associated with function in univariate $^{6}$ and multivariate analyses ${ }^{7}$. Landewé, et $a l^{11}$ reported in a longitudinal analysis over 2 years that disease activity and radiographic damage assessed by the modified Stoke Ankylosing Spondylitis Spine Score (mSASSS) were independent contributors of change in function after adjusting for age and sex.

The aim of our study was to assess (1) the relationship between the broad range of clinical characteristics of patients with AS and radiographic spinal damage; and (2) the influence of spinal changes, in addition to the clinical characteristics, on functional outcome.

\section{MATERIALS AND METHODS}

Rheumatologists and patients. Between February 2004 and February 2005, all 204 Belgian rheumatologists were invited to register their patients with AS for an epidemiologic study. A random subsample of patients was included in a cross-sectional clinical study. Those fulfilling the modified New York criteria for definite $\mathrm{AS}^{12}$ and having a spinal radiographic examination within 2 years were considered for analyses.

The study was approved by the national license bureau for noninterventional research, and all patients provided signed informed consent prior to inclusion. A detailed description of the sampling and epidemiology of rheumatologists and patients is described elsewhere ${ }^{13}$.

Clinical characteristics and functional outcome. A questionnaire was completed by the treating rheumatologist based on the patients' records and included the items of the modified New York criteria ${ }^{12}$, age at symptom onset, the presence of HLA-B27 antigen, the last available value of C-reactive protein (CRP), and the history of past or present peripheral arthritis, enthesitis and extraarticular disease. Extraarticular disease manifestations included anterior uveitis, psoriasis, ulcerative colitis, and Crohn's disease [combined and referred to as irritable bowel disease (IBD)]. To assess disease activity patients completed the Bath AS Disease Activity Index (BAS$\mathrm{DAI})^{14}$, and to assess limitations in mobility, they underwent a clinical examination by the rheumatologist, who recorded the components of the Bath AS Metrology Index (BASMI) ${ }^{15}$. Physical function was assessed through the self-reported Bath AS Functional Index (BASFI) ${ }^{16}$.

Radiographic changes. Consistent with the naturalistic design of the study, information on radiographic abnormalities was based on the latest available documents if not performed at the time of the study visit and were scored by the treating rheumatologist. The sacroiliac joints were scored according to the modified New York criteria. Spinal radiographic changes had to be classified into 3 (exclusive) categories: (1) no spinal abnormalities related to AS; (2) presence of syndesmophytes; or (3) presence of spinal ankylosis.

Statistical analyses. Descriptive statistics were used to describe the data by the calculation of means with standard deviation and range for continuous data and frequencies for dichotomous and ordinal data. Differences and inferences between the 3 subgroups with different spinal changes were tested by computing odds ratios and $95 \%$ confidence intervals. Associated $p$ values were calculated by chi-square statistics for dichotomous data and Kruskal-Wallis tests for continuous data.
To explore the effect of one or more variables on radiographic changes, a logit link function (ordinal logistic regression) was used, first correcting for the potential confounders age at onset, disease duration since symptom onset, and sex. Variables were HLA-B27, elevated CRP, extraspinal manifestations (ever hip arthritis, arthritis, or enthesitis) and extraarticular manifestations (uveitis, psoriasis, and IBD). Interactions between the sets of variables were explored in additional analyses that included for the main effect variables and the interaction term for each interaction studied. The exponents of the estimates of those ordinal logistic regression analyses can be interpreted as odds ratios for each level of radiographic change.

To determine the effect of variables on BASFI, generalized linear regression models were computed, first correcting for confounders age, disease duration, sex, and disease activity (BASDAI). Other variables were spinal radiographic changes, presence of extraspinal manifestations, and extraarticular manifestations. When needed, variable selection and model comparison was performed by goodness of fit summaries (Akaike information criterion). Interaction terms were checked where noted. These models were repeated in a subsample of patients that had BASMI data $(n=360)$ to account for the association of variables with radiographic spinal changes in view of BASMI.

For all regression models, underlying assumptions of the models were checked. Missing completely at random (MCAR) was assumed. Missing cases were excluded, pair-wise for demographic explorations and list-wise for the regression models. The validity of the MCAR assumption was checked and more detailed analysis of missingness was performed when needed. All analyses were performed in SPSS 15.0.

\section{RESULTS}

Rheumatologists and patient characteristics. Eighty-nine of 204 invited rheumatologists (44\%) agreed to participate and represented all the geographical regions of Belgium as well as a mix of academic and nonacademic practices. A total of 1023 patients were included in the study. All patients fulfilled the modified New York criteria, of whom $847(83 \%)$ met the criteria for definite AS and $176(17 \%)$ the criteria for probable AS. Six hundred nineteen $(72 \%)$ patients with definite AS had radiographs available from the last 2 years. Sixty-seven percent were male, with a mean age of 43.9 $( \pm 12.1)$ years, and mean disease duration since symptom onset was $17.5( \pm 12.2)$ years. In addition, $83 \%$ were HLA-B27-positive.

Radiographic spinal change was recorded in 294 of 619 patients $(47 \%)$. One hundred twenty-four (20\%) had spinal ankylosis, 170 (27\%) syndesmophytes, and 325 (53\%) no spinal abnormalities related to AS. A cumulative history of peripheral arthritis was recorded in 351 (56.8\%) patients, enthesitis in $215(47.7 \%)$, and hip involvement in 166 $(26.6 \%)$. A hip arthroplasty had been performed in 36 $(5.8 \%)$ patients. Twenty-seven percent of patients had spinal changes as well as peripheral arthritis and 155 (25\%) had neither radiographic change nor arthritis. A cumulative history of extraarticular manifestations was registered for uveitis in 169 patients $(27.3 \%)$, psoriasis in $68(11.0 \%)$, and IBD in $54(8.7 \%)$. Forty percent of patients had at least one extraarticular manifestation.

Missing data. Patients with a missing radiographic evaluation were older, 46.6 versus 43.9 years (difference 2.7 yrs; 95\% CI 0.7-0.4), had longer symptom duration, 13.6 versus 
11.4 years (difference $2.2 \mathrm{yrs} ; 95 \% \mathrm{CI}-0.15$ to 3.8 ), and had slightly better physical functioning on BASFI, 4.8 versus 5.2 (difference $0.4 ; 95 \%$ CI $0.08-0.73$ ), but did not differ with respect to sex, peripheral arthritis or hip involvement, or HLA-B27 status. From 619 patients with radiographic evaluations, HLA-B27 data were available in $78 \%$ and complete BASMI in $58 \%$, the remaining $42 \%$ having incomplete BASMI measurements. Patients with missing HLA-B27 were older, 46.9 compared to 42.4 years (difference $4.5 \mathrm{yrs}$; 95\% CI 2.6-6.5), and patients with missing BASMI had higher BASDAI, 5.8 versus 5.1 (difference 0.7 ; 95\% CI $0.4-1.0$ ), and BASFI, 5.7 versus 4.9 (difference $0.8 ; 95 \%$ CI $0.4-1.2)$.

Characteristics of patients according to radiographic subgroup. Table 1 describes the differences in patients' characteristics in terms of their radiological involvement (no AS-related spinal abnormalities, syndesmophytes, or spinal ankylosis). No differences in age at onset of axial symptoms or BASDAI or elevated CRP could be found. In contrast, more radiographic spinal changes were significantly associated with longer disease duration and worse BASFI and BASMI scores. Twenty-seven percent of patients with symptom duration $<10$ years showed AS-related radiographic spinal changes (syndesmophytes or ankylosis). This proportion increased to $77 \%$ in patients with more than 30 years' symptom duration.

Factors associated with radiographic spinal changes. The ordinal regression models first confirmed that age at onset, symptom duration, and sex were confounders (Table 2; first section). A significant interaction between disease duration and sex was found, indicating that male patients not only had more frequent spinal changes but were also more likely to have an increase in spinal changes when disease duration increased. Figure 1 shows the proportion of men and women with spinal ankylosis for cohorts with disease duration $<10$ years, $10-30$ years, and $\geq 30$ years.
Table 2. Association of demographic, extraspinal, and extraarticular manifestations with radiographic spinal changes.

\begin{tabular}{lcc}
\hline & $\operatorname{exp~B~(OR)~}$ & $95 \%$ CI \\
\hline Age at onset & 0.03 & $0.02-0.05$ \\
Symptom duration & 0.09 & $0.07-1.01$ \\
Sex & 1.67 & $1.27-2.08$ \\
Estimate when controlling for age at onset, sex, and disease duration \\
Hip involvement, disease duration & 0.61 & $0.24-0.98$ \\
Peripheral arthritis & 0.30 & $-0.04-0.64$ \\
Enthesitis & 0.08 & $-0.14-0.24$ \\
Uveitis & 0.31 & $-0.06-0.72$ \\
Psoriasis & 0.10 & $-0.43-0.62$ \\
Inflammatory bowel disease & -0.37 & $-0.96-0.21$ \\
\hline
\end{tabular}

In the second step, the different extraspinal and extraarticular manifestations (hip changes, peripheral arthritis, enthesitis, uveitis, psoriasis, IBD) were added to this model. Hip involvement was the only variable associated with radiographic spinal changes (Table 2; section 2). Further analysis of interaction terms showed significant interaction between symptom duration and hip involvement, indicating that patients with hip involvement were more likely to have an increase in spinal changes when disease duration increased.

Variables associated with BASFI. General linear regression analyses showed that age, BASDAI, radiographic changes, and hip involvement, but not sex, disease duration, peripheral arthritis, enthesitis, uveitis, psoriasis, or IBD, contributed to physical function measured by BASFI (Table 3). No significant interactions were found in this final model. A second series of models in the subsample of patients with BASMI $(n=360)$ aimed to evaluate the association between radiographic spinal changes in view of BASMI. First, the initial model (described above) was confirmed as the estimates for beta were comparable, indicating the MCAR assumption could be considered valid. Adding the BASMI

Table 1. Characteristics of patients with definite AS (modified New York criteria) and available radiographic examination according to the degree of radiographic change.

\begin{tabular}{lcccc}
\hline & $\begin{array}{c}\text { No AS } \\
\text { Abnormalities, } \\
\mathrm{n}=325\end{array}$ & $\begin{array}{c}\text { Syndesmophytes, } \\
\mathrm{n}=170\end{array}$ & $\begin{array}{c}\text { Spinal Ankylosis, } \\
\mathrm{n}=124\end{array}$ & $\mathrm{p}$ \\
& & & \\
\hline Age at onset, yrs, mean (SD) & $26.8(10.7)$ & $27.2(11.8)$ & $24.3(10.9)$ & 0.03 \\
$\quad$ [range] & {$[3.5-64.5]$} & {$[4.1-62.7]$} & {$[5.3-63.2]$} & \\
Symptom duration, yrs, mean (SD) & $13.6(10.7)$ & $18.1(10.8)$ & $26.9(12.8)$ & $<0.001$ \\
[range] & {$[1-52.7]$} & {$[1-47.9]$} & {$[2-66.2]$} & $<0.001$ \\
Male, \% & 53 & 80 & 88 & 0.07 \\
HLA-B27 (n = 489), \% & 80 & 89 & 87 & 0.03 \\
Elevated CRP (n = 584), \% & 31 & 45 & 45 & 0.5 \\
BASDAI, mean (SD) & $5.4(2.0)$ & $5.3(2.1)$ & $5.6(1.9)$ & $<0.001$ \\
BASFI, mean (SD) & $4.7(2.4)$ & $5.2(2.5)$ & $6.5(2.2)$ & $<0.001$ \\
BASMI (n = 360), mean (SD) & $2.4(1.6)$ & $3.8(2.2)$ & $6.8(2.4)$ & \\
\hline
\end{tabular}

CRP: C-reactive protein; BASDAI: Bath AS Disease Index; BASFI: Bath AS Functional Index; BASMI: Bath AS Metrology Index. 


\section{Females}
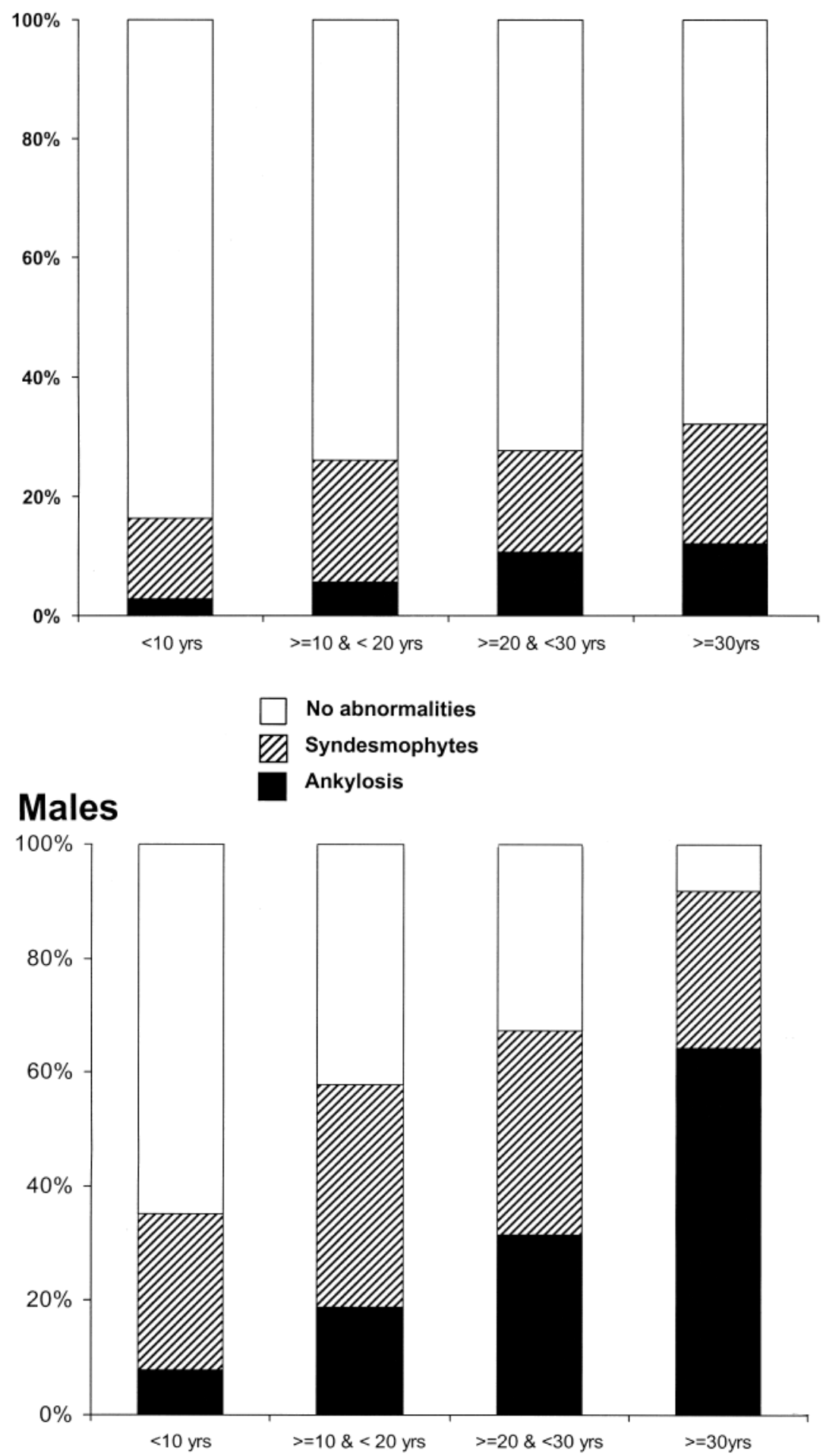

Figure 1. Cumulative prevalence of radiographic syndesmophytes and ankylosis according to disease duration for male $(n=417)$ and female $(n=202)$ patients.

to the explanatory variables revealed a strong association between BASMI and BASFI (beta 0.33, 95\% CI 0.24-0.41). However, the contribution of radiographic changes disappeared and the strength of the association with hip involve- ment decreased, indicating BASMI was a mediator for these variables. The model including BASMI (confounders, BASMI, and hip involvement) had a better goodness of fit compared to the model without BASMI (confounders, 
Table 3. Association of demographic, clinical, and disease characteristics with physical functioning (Bath AS Functional Index).

\begin{tabular}{lcc}
\hline & Beta & $95 \%$ CI \\
\hline Intercept & -1.52 & -2.1 to -0.9 \\
Age & 0.04 & $0.02-0.05$ \\
Female sex & 0.13 & $-0.17-0.40$ \\
Symptom duration & -0.003 & $-0.02-0.11$ \\
BASDAI & 0.86 & $0.92-0.19$ \\
Radiographic spinal change & & \\
$\quad$ Ankylosis & 1.13 & $0.74-1.52$ \\
Syndesmophytes & 0.42 & $0.11-0.74$ \\
$\quad$ No abnormalities & Reference & \\
Hip involvement & 0.64 & $0.35-0.92$ \\
\hline
\end{tabular}

radiographic changes, and hip involvement) as shown by the improvement of the Akaike information criterion ("smaller is better"), which decreased from 1335 to 1281 .

\section{DISCUSSION}

We evaluated characteristics of patients with AS who had radiographic spinal changes. There were no radiographic spinal changes in $53 \%$ of the total group; however, in the subgroup with disease duration longer than 30 years, only $23 \%$ remained without spinal changes. This suggests that a large majority of patients under care of a rheumatologist have spinal involvement that will eventually lead to changes visible on conventional radiographs. The likelihood of spinal ankylosis was also higher in men, in those with symptom onset at an earlier age, and in patients who had a history of hip involvement. There was no association of HLAB27 or extraspinal articular disease or extraarticular manifestations with spinal ankylosis.

While it does not seem surprising that disease duration is associated with radiographic changes, there are few prospective longterm studies with data that quantify this observation. The Outcome Assessments in Ankylosing Spondylitis International Study evaluated a cohort of patients under the care of a rheumatologist, and in radiographs scored using the mSASSS (score range 0-72) ${ }^{17}$, it was shown that over a period of 4 years the average change in score was low, but on the patient level and depending on the criterion, between $37 \%$ and $57 \%$ of patients had an increase in the spinal scoring system ${ }^{18}$. Dawes ${ }^{19}$ reported an average increase of 23 points in mSASSS over 9 years in a group of patients with at least 2 radiographic assessments available. As in our study, Dawes also noted that earlier onset of symptoms was associated with more AS-related radiographic changes.

The increased prevalence and severity of radiographic spinal changes in men and in those with hip involvement confirms previous reports and adds to the evidence ${ }^{4-7,9,20-27}$. The explanation for the gender difference remains unclear. Although there is no linkage between X-chromosome markers and susceptibility for $\mathrm{AS}^{28}$, it cannot be excluded that severity of AS is X-link determined. Polymorphisms of genes that control tissue calcification and arthritis have been found to be associated with AS, and their relationship with sex is under investigation ${ }^{29-31}$. The previously observed association between spinal involvement and hip arthritis resulted in the classification of hips as "root" or "axial" joints. No pathophysiological model investigated whether the disease processes in the spine are similar to that in the hips. This remains an interesting area for future research.

In our study radiographic spinal change was a relevant contributor to physical function, together with age and disease activity (BASDAI) and hip involvement. Interestingly, gender had no influence on function, and also did not influence the univariate analyses, despite the higher frequency of radiographic changes among men. In the subgroup of patients with BASMI data, the effect of radiographic change on BASFI disappeared and the influence of hip involvement decreased when taking spinal and hip mobility (BASMI) into account, and improved the goodness of fit of the model. This suggests that an important part of the effect of the radiographic changes on the BASFI can be explained by its effect on the BASMI. The contribution of radiographic changes over time to the BASFI or the Dougados Functional Index was confirmed by Landewé, et al in a study that applied mSASSS to score the extent of radiographic changes ${ }^{11}$. Similarly to our study, the BASDAI also was a determinant of physical function. Of note, the relation between radiographic changes was shown not only for the syndesmophyte score, but also for the non-syndesmophyte score (squaring of sclerosis erosions). The independent contribution of BASMI data was not explored in this study. Maksymowych, et al have described strong univariate associations between spinal mobility (using the Edmonton AS Metrology Index; EDASMI) and function (BASFI) or radiographic changes $(\mathrm{mSASSS})^{32}$. Again, the combined contribution of spinal and radiographic change to function was not investigated. It should be emphasized that although BASMI relates to radiographic damage on the group level, this does not necessarily imply that radiographic staging on the individual level can be replaced by the $\mathrm{BASMI}^{33}$. It was surprising in our study that enthesitis or peripheral arthritis had a low impact on function. It is possible that BASFI is not sensitive for the functional influence of peripheral joint involvement, since this instrument primarily focuses on spinal functioning. Also, physician-reported enthesitis might not be accurate. This might explain why the Spondyloarthritis Research Consortium of Canada enthesitis index showed a significant correlation with BASFI in the validation study ${ }^{34}$.

Some limitations of our study should be noted. First, the data were collected cross-sectionally and therefore do not allow the conclusion that variables associated with spinal changes are "prognostic" factors. Also, left censorship may have occurred, referring to the phenomenon that patients with less severe disease refrained from further control or had 
no radiographic assessment and therefore the group with longer disease is a selection of patients with worse disease. It is unlikely that this influences the observed relation with sex, since in the cohorts with different disease duration, no differences in prevalence of both sexes were seen. Second, these results pertain to patients with AS under care of a rheumatologist, which will certainly bias toward more severe disease, potentially explaining the large prevalence of ankylosis and extraspinal articular manifestations, especially peripheral arthritis. On the other hand, the study population is relevant, since it represents the population where more intensive treatment will be considered. Nevertheless, due to this source of sampling and the left censorship, the absolute figures on prevalence of radiographic spinal changes should be interpreted with caution. Finally, the design of the study did not allow standardizing the instruments to assess articular and extraspinal disease and radiographic changes. It is difficult to hypothesize whether physician-reported enthesitis, arthritis, or hip involvement will result in under- or over-reporting. As noted, the absence of a standardized method to report enthesitis could explain why our study did not find an association with function ${ }^{34}$. When interpreting the relevance of hip involvement, an important factor to explain spinal changes as well as function, the issue of standardization is pertinent. It should be emphasized, however, that similar strong relationships remained when replacing hip involvement with hip arthroplasty. The classification of radiographic changes into the 3 groups by physicians could have led to overlap between the groups with "syndesmophytes" and those with "ankylosis," since the threshold at which consecutive bridging syndesmophytes are considered "spinal ankylosis" is likely different for each rheumatologist. However, the data suggest that the group classified as "spinal ankylosis" show more extensive radiographic effects than the group classified as "syndesmophytes." The terminology "radiographic spinal changes" was chosen carefully. Patients can have spinal involvement (pain and stiffness) without changes seen on conventional radiology. There is increasing insight that the structural spinal changes in AS reflect the pathophysiologic remodelling as a consequence of either inflammation or other stress on the joint and therefore are "reparative" and not just "destructive" 35 . A timeframe of 2 years was allowed to include radiographs. It is unlikely this influenced our results since it has been shown that on the group level the radiographic progression over 2 years in an unselected cohort was low, although clear changes were seen at the patient level after 2 years ${ }^{36}$.

The major strength of our study is the large number of patients with AS that were recorded and assessed. This allowed sufficient power to study the relationships of disease manifestations that are present in only a minority of patients.
Almost $47 \%$ of patients with AS under care of a rheumatologist had radiographic spinal changes. Patient's sex and hip involvement, but not uveitis, IBD, peripheral arthritis or psoriasis, were associated with spinal changes. Radiological change contributed to worse physical functioning, but on the group level the presence of radiographic changes seemed to be interchangeable with assessment of spinal mobility assessed by BASMI.

\section{ACKNOWLEDGMENT}

The authors thank Hermine Leroy and Jackeline Mercerau of Denys Research Centre, Belgium, and Jean Paul Brasseur of Schering Plough Belgium for assistance in data management; and Wim Noel, Centocor Belgium, for assistance with the literature review.

The participating rheumatologists: Christine Ackerman, Valérie Badot, Pierre Bastien, Hubert Berghs, Valérie Bonnet, Bernard Bouchez, Yves Boutsen, Etienne Coigne, Marleen Coppens, Luk Corluy, Françoise Cornet Thiry, Patrick Coutellier, Stéphane Daens, Silvano Dall'Armellina, Florence Daumerie, Griet De Brabanter, Valérie DeDecker, Kathleen Declerck, Eric Dhondt, Silvana Di Romana, Christian Docquier, Françoise Duckerts, Laurence Dujardin, Jean-Paul Engelbeen, Maria-José Fernandez-Lopez, Danielle Focan-Henrard, Marie-Anne Fontaine, Dominique François, Piet Geusens, Geert Ghyselen, Stefan Goemaere, Lieve Gyselbrecht, Robert Halleux, Elisabeth Heuse, Alain Heylen, AnneMarie Huynen-Jeugmans, Carlos Immesoete, Xavier Janssens, Dimitri Jardinet, Rik Joos, Elli Kruithof, Christine Langenaken, Catherine Leens, Daniel Lefèbvre, Sophie Lefèbvre, Jan Lenaerts, Frank Luyten, Kristin Maenaut, Martin Maertens, Beatrix Maeyaert, Herman Mielants, Alain Mindlin, Muriel Moris, Adrien Nzeusseu, Christian Pater, Anne Peretz, Johan Praet, Jiangang Qu, Frank Raeman, Ruth Reychler, Isabelle Ronsmans, Nathalie Sarlet, Godelieve Schatteman, Anne Sileghem, Geert Stappaerts, Pierre Stasse, Serge Steinfeld, Veerle Taelman, Laure Tant, Francis Toussaint, Nancy Van Den Bossche, Xavier Van Mullen, Paul Van Wanghe, Marc Vanden Berghe, Marthe Vanden Berghe, Johan Vanhoof, Ann Verbruggen, Léon Verbruggen, Wilfried Verdickt, Pascale Volders, Philippe Vroninks, René Westhovens, Luc Williame, Micheline Wouters, Hans Georg Zmierczak.

\section{REFERENCES}

1. van der Linden SM, Valkenburg HA, de Jongh BM, Cats A. The risk of developing ankylosing spondylitis in HLA-B27 positive individuals. A comparison of relatives of spondylitis patients with the general population. Arthritis Rheum 1984;27:241-9.

2. Rudwaleit M, Khan MA, Sieper J. The challenge of diagnosis and classification in early ankylosing spondylitis: do we need new criteria? Arthritis Rheum 2005;52:1000-8.

3. van der Linden S, van der Heijde D. Ankylosing spondylitis. Clinical features. Rheum Dis Clin North Am 1998;24:663-76, vii.

4. Spencer DG, Park WM, Dick HM, Papazoglou SN, Buchanan WW. Radiological manifestations in 200 patients with ankylosing spondylitis: correlation with clinical features and HLA-B27. J Rheumatol 1979;6:305-15.

5. Brophy S, Mackay K, Al-Saidi A, Taylor G, Calin A. The natural history of ankylosing spondylitis as defined by radiological progression. J Rheumatol 2002;29:1236-43.

6. Lee W, Reveille JD, Davis JC Jr, Learch TJ, Ward MM, Weisman $\mathrm{MH}$. Are there gender differences in severity of ankylosing spondylitis? Results from the PSOAS cohort. Ann Rheum Dis 2007;66:633-8

7. Doran MF, Brophy S, Mackay K, Taylor G, Calin A. Predictors of longterm outcome in ankylosing spondylitis. J Rheumatol 2003;30:316-20.

8. Calin A, Mackay K, Santos H, Brophy S. A new dimension to Personal non-commercial use only. The Journal of Rheumatology Copyright (c 2009. All rights reserved. 
outcome: application of the Bath Ankylosing Spondylitis Radiology Index. J Rheumatol 1999;26:988-92.

9. Averns HL, Oxtoby J, Taylor HG, Jones PW, Dziedzic K, Dawes PT. Radiological outcome in ankylosing spondylitis: use of the Stoke Ankylosing Spondylitis Spine Score (SASSS). Br J Rheumatol 1996;35:373-6.

10. Taylor HG, Wardle T, Beswick EJ, Dawes PT. The relationship of clinical and laboratory measurements to radiological change in ankylosing spondylitis. Br J Rheumatol 1991;30:330-5.

11. Landewe R, Dougados M, Mielants H, van der Tempel H, van der Heijde D. Physical function in ankylosing spondylitis is independently determined by both disease activity and radiographic damage of the spine. Ann Rheum Dis 2008 Jul 15. [Epub ahead of print]

12. van der Linden S, Valkenburg HA, Cats A. Evaluation of diagnostic criteria for ankylosing spondylitis. A proposal for modification of the New York criteria. Arthritis Rheum 1984;27:361-8.

13. Vander Cruyssen B, Ribbens C, Boonen A, et al. The epidemiology of ankylosing spondylitis and the commencement of anti-TNF therapy in daily rheumatology practice. Ann Rheum Dis 2007;66:1072-7.

14. Garrett $\mathrm{S}$, Jenkinson T, Kennedy LG, Whitelock H, Gaisford P, Calin A. A new approach to defining disease status in ankylosing spondylitis: the Bath Ankylosing Spondylitis Disease Activity Index. J Rheumatol 1994;21:2286-91.

15. Jenkinson TR, Mallorie PA, Whitelock HC, Kennedy LG, Garrett SL, Calin A. Defining spinal mobility in ankylosing spondylitis (AS). The Bath AS Metrology Index. J Rheumatol 1994;21:1694-8.

16. Calin A, Garrett S, Whitelock H, et al. A new approach to defining functional ability in ankylosing spondylitis: the development of the Bath Ankylosing Spondylitis Functional Index. J Rheumatol 1994;21:2281-5.

17. Creemers MC, Franssen MJ, van 't Hof MA, Gribnau FW, van de Putte LB, van Riel PL. Assessment of outcome in ankylosing spondylitis: an extended radiographic scoring system. Ann Rheum Dis 2005;64:127-9.

18. Wanders AJ, Landewe RB, Spoorenberg A, et al. What is the most appropriate radiologic scoring method for ankylosing spondylitis? A comparison of the available methods based on the Outcome Measures in Rheumatology Clinical Trials filter. Arthritis Rheum 2004;50:2622-32.

19. Dawes PT. Stoke Ankylosing Spondylitis Spine Score. J Rheumatol 1999;26:993-6.

20. Gran JT, Ostensen M, Husby G. A clinical comparison between males and females with ankylosing spondylitis. J Rheumatol 1985;12:126-9.

21. Will R, Edmunds L, Elswood J, Calin A. Is there sexual inequality in ankylosing spondylitis? A study of 498 women and 1202 men. J Rheumatol 1990;17:1649-52.
22. Resnick D, Dwosh IL, Goergen TG, et al. Clinical and radiographic abnormalities in ankylosing spondylitis: a comparison of men and women. Radiology 1976;119:293-7.

23. Levitin PM, Davis JS. Proceedings: Ankylosing spondylitis in women. Arthritis Rheum 1975;18:528.

24. Jimenez-Balderas FJ, Mintz G. Ankylosing spondylitis: clinical course in women and men. J Rheumatol 1993;20:2069-72.

25. Braunstein EM, Martel W, Moidel R. Ankylosing spondylitis in men and women: a clinical and radiographic comparison. Radiology 1982;144:91-4.

26. Kidd B, Mullee M, Frank A, Cawley M. Disease expression of ankylosing spondylitis in males and females. J Rheumatol 1988;15:1407-9.

27. Eustace S, Coughlan RJ, McCarthy C. Ankylosing spondylitis. A comparison of clinical and radiographic features in men and women. Ir Med J 1993;86:120-2.

28. Hoyle E, Laval SH, Calin A, Wordsworth BP, Brown MA. The $\mathrm{X}$-chromosome and susceptibility to ankylosing spondylitis. Arthritis Rheum 2000;43:1353-5.

29. Ho AM, Johnson MD, Kingsley DM. Role of the mouse ank gene in control of tissue calcification and arthritis. Science 2000;289:265-70

30. Tsui FW, Tsui HW, Cheng EY, et al. Novel genetic markers in the 5 '-flanking region of ANKH are associated with ankylosing spondylitis. Arthritis Rheum 2003;48:791-7.

31. Tsui HW, Inman RD, Paterson AD, Reveille JD, Tsui FW. ANKH variants associated with ankylosing spondylitis: gender differences. Arthritis Res Ther 2005;7:R513-25.

32. Maksymowych W, Mallon C, Richardson R, et al. Development and validation of the Edmonton Ankylosing Spondylitis Metrology Index. Arthritis Rheum 2006;55:575-82.

33. Wanders A, Landewe R, Dougados M, Mielants H, van der Linden $\mathrm{S}$, van der Heijde D. Association between radiographic damage of the spine and spinal mobility for individual patients with ankylosing spondylitis: can assessment of spinal mobility be a proxy for radiographic evaluation? Ann Rheum Dis 2005;64:988-94.

34. Maksymowych W, Mallon C, Morrow S, et al. Development and validation of the Spondyloarthritis Research Consortium of Canada (SPARCC) Enthesitis Index. Ann Rheum Dis 2008 Jun 4. [Epub ahead of print]

35. Schett G, Landewe R, van der Heijde D. Tumour necrosis factor blockers and structural remodelling in ankylosing spondylitis: what is reality and what is fiction? Ann Rheum Dis 2007;66:709-11.

36. Spoorenberg A, de Vlam K, van der Linden S, et al. Radiological scoring methods in ankylosing spondylitis. Reliability and change over 1 and 2 years. J Rheumatol 2004;31:125-32. 